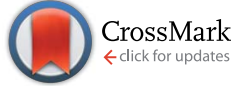

Cite this: RSC Adv., 2015, 5, 22899

\title{
Blue fluorogenic probes for cell plasma membranes fill the gap in multicolour imaging $\dagger$
}

\author{
Rémy Kreder, ${ }^{a}$ Sule Oncul, ${ }^{\text {ab }}$ Oleksandr A. Kucherak, ${ }^{a}$ Kyrylo A. Pyrshev, ${ }^{\text {ac }}$ \\ Eleonore Real, ${ }^{a}$ Yves Mély ${ }^{a}$ and Andrey S. Klymchenko*a
}

Blue fluorescent probes for cellular imaging are poorly developed and rarely used because of strong cell auto-fluorescence at these wavelengths. However, multi-colour imaging needs blue probes, such as ubiquitous nucleus markers DAPI and Hoechst, because they can be readily combined with common green and red markers based on dyes and fluorescent proteins. Cell plasma membrane is an important target for imaging, but membrane probes that absorb and emit light between 400 and $500 \mathrm{~nm}$ are missing. Here, using 3-methoxychromone dyes we designed two blue membrane probes exhibiting $>100$-fold fluorescence turn-on (fluorogenic response) on membrane binding, large Stokes shift (70-90 $\mathrm{nm}$ ) as well as high brightness and photostability. These unique properties enabled cellular imaging at low probe concentrations (20-50 nM) with minimal background from cell auto-fluorescence and from free probe. RGB multicolour imaging was successfully realized using these probes in combination with common green and red markers. As the new probes enable high-quality imaging of cell plasma membranes in the poorly explored blue spectral region, they may become popular tools that fill the gap in multi-colour microscopy.

Received 11th December 2014 Accepted 20th February 2015

DOI: $10.1039 / c 4 r a 16225 k$

www.rsc.org/advances as wheat germ agglutinin (WGA). ${ }^{18}$ Among the existing molecular membrane probes, two large families, namely fluorescently labelled lipids and specially designed probes, should be mentioned. Labelled lipids are ideal for model membranes, but their use for living cells requires special lipid delivery systems, such as cyclodextrins. ${ }^{19}$ The second class is based on specially designed fluorescent probes, which can spontaneously stain lipid membranes without using delivery agents. ${ }^{5-7,11-13,15}$ To achieve specific staining of cell plasma membranes with minimal internalization, fluorescent dyes are usually modified with a polar head group, as it was done for FM4-64, ${ }^{20}$ TMA-DPH, ${ }^{21}$ di-4-ANEPPDHQ ${ }^{22}$ C-Laurdan, ${ }^{23}$ Mem-SQAC, ${ }^{24}$ push-pull glycoconjugates, ${ }^{12}$ and oligothiophene amphiphiles. ${ }^{11}$ We should also mention F2N12S ${ }^{25}$ and NR12S, ${ }^{13}$ bearing an amphiphilic anchor group that enables specific staining of the outer membrane leaflet with minimal internalization and flip-flop between the leaflets. ${ }^{13}$ However, the membrane probes developed so far, being highly useful for studying biomembranes, ${ }^{5}$ overlap with the 500 to $650 \mathrm{~nm}$ spectral window of common molecular probes and fluorescent proteins, ${ }^{26}$ which limit their applications for multi-colour imaging. Exceptions are TMA-DPH and C-Laurdan and their analogues, but these probes require ultraviolet excitation $(\sim 360 \mathrm{~nm})$, which is harmful for the cells. Therefore, there is a strong need for powerful blue probes for cell plasma membranes, which, similarly to DAPI and Hoechst, the blue stains of nucleus, could become ubiquitous cell imaging tools. These blue probes should be excitable by violet light $(\sim 400 \mathrm{~nm})$,
${ }^{a}$ Laboratoire de Biophotonique et Pharmacologie UMR 7213 CNRS/Université de Strasbourg, Illkirch, France. E-mail: andrey.klymchenko@unistra.fr

${ }^{b}$ Istanbul Medeniyet University, School of Medicine, Department of Biophysics, Istanbul, Turkey

'Laboratory of Nanobiotechnologies, Department of Molecular immunology, Palladin Institute of biochemistry of NASU, Kiev, 01601, Ukraine

$\dagger$ Electronic supplementary information (ESI) available. See DOI: 10.1039/c4ra16225k 
emit efficiently around 450-500 $\mathrm{nm}$ and exhibit large Stokes shift in order to minimize the contribution of cell autofluorescence, commonly observed in the blue spectral region. Moreover, they should be fluorogenic, i.e. non-fluorescent in water but highly fluorescent in lipid membranes, which would enable imaging without background noise from the non-bound probes. ${ }^{27,28}$ As prospective building blocks for preparation of blue membrane probes, we considered 3-methoxychromones, because they were recently shown to be bright and photostable, and to exhibit large Stokes shift and fluorogenic response to solvent polarity. ${ }^{29}$

In the present work using 3-methoxychromone dyes, we developed the first high-performance blue membrane probes, characterized by high brightness and photostability as well as by suitable absorption and emission wavelengths, allowing their combination with green and red markers. We showed that these probes could be used at concentrations as low as 20-50 $\mathrm{nM}$ and that their high brightness, large Stokes shift and efficient membrane binding with fluorogenic response provided excellent signal-to-noise ratio in cellular imaging.

\section{Experimental}

\subsection{Synthesis of probes}

All chemicals and solvents for synthesis were from SigmaAldrich. Synthesis of F2N12S was described elsewhere. ${ }^{25}$

2-(6-(Diethylamino)benzofuran-2-yl)-3-hydroxy-6-(methoxymethyl)-4H-chromen-4-one (1). 6-(Diethylamino)benzofuran-2carbaldehyde $^{30}$ (1 eq., $1 \mathrm{~g}$ ) and 5-chloromethyl-2-hydroxyacetophenone $^{31}$ (1 eq., $0.85 \mathrm{~g}$ ) were dissolved in $10 \mathrm{~mL}$ of cold DMF (ice bath) and then treated with $0.5 \mathrm{~g}$ sodium methoxide ( 4 eq., $1 \mathrm{~g}$ ). The obtained mixture was stirred for $24 \mathrm{~h}$ to give dark read chalcone, which was used in the next step without isolation. This mixture was then diluted with $40 \mathrm{~mL}$ of ethanol followed by addition of sodium methoxide (12 eq., $1.5 \mathrm{~g}$ ) and hydrogen peroxide (10 eq., $2.3 \mathrm{~mL}$ ). The mixture was shaken intensively and heated gently to reflux. Within $5 \mathrm{~min}$, the dark red solution turned orange. Then, the solution was rapidly cooled to room temperature (RT) and poured into water. The product was then extracted with dichloromethane. The solvent was removed under vacuum and the crude product was purified by column chromatography with dichloromethane/MeOH (95/ $5)$ as an eluent. Yellow powder, yield $19 \% .{ }^{1} \mathrm{H}$ NMR $(400 \mathrm{MHz}$, chloroform- $d$ ) $\delta 8.20(\mathrm{~s}, 1 \mathrm{H}), 7.75-7.63(\mathrm{~m}, 3 \mathrm{H}), 7.50(\mathrm{~d}, J=8.8$ $\mathrm{Hz}, 1 \mathrm{H}), 6.89(\mathrm{~d}, J=2.2 \mathrm{~Hz}, 1 \mathrm{H}), 6.78(\mathrm{dd}, J=8.8,2.2 \mathrm{~Hz}, 1 \mathrm{H})$, 4.59 (s, 1H), 3.53-3.43 (m, 7H), 1.26 (t, $J=7.0 \mathrm{~Hz}, 6 \mathrm{H})$. HR-LCMS: $(\mathrm{m} / \mathrm{z}) \mathrm{C}_{23} \mathrm{H}_{23} \mathrm{NO}_{5}$ calc. 393.1576, found 393.1592.

6-(Bromomethyl)-2-(6-(diethylamino)benzofuran-2-yl)-3-hydroxy4H-chromen-4-one (2). 2-(6-(Diethylamino)benzofuran-2-yl)-3hydroxy-6-(methoxymethyl)-4H-chromen-4-one (1) (1 eq., 260 $\mathrm{mg}$ ) was dissolved in a hydrobromic acid solution $(48 \%)(5 \mathrm{~mL})$ and the mixture was heated for $10 \mathrm{~min}$ at $100{ }^{\circ} \mathrm{C}$. The reaction was then cool down to RT and neutralized with a solution of $\mathrm{NaOH}(50 \%)$ ( $2 \mathrm{~mL}$ ). The obtained brown orange precipitate was filtrated and washed with $15 \mathrm{~mL}$ of heptane. The product was dried and used directly without further purification. Brown red powder, yield 85\%. ${ }^{1} \mathrm{H}$ NMR (400 MHz, chloroform- $d$ ) $\delta 8.27$ $(\mathrm{d}, J=2.3 \mathrm{~Hz}, 1 \mathrm{H}), 7.78-7.73(\mathrm{~m}, 1 \mathrm{H}), 7.67(\mathrm{~d}, J=11.2 \mathrm{~Hz}, 2 \mathrm{H})$, $7.50(\mathrm{~d}, J=8.7 \mathrm{~Hz}, 1 \mathrm{H}), 6.88(\mathrm{~s}, 1 \mathrm{H}), 6.81-6.76(\mathrm{~m}, 1 \mathrm{H}), 4.63(\mathrm{~s}$, 2H), 3.48 (q, $J=7.0 \mathrm{~Hz}, 4 \mathrm{H}), 1.26$ (t, $J=7.0 \mathrm{~Hz}, 6 \mathrm{H})$. HR-LC-MS: $(\mathrm{m} / \mathrm{z}) \mathrm{C}_{22} \mathrm{H}_{20} \mathrm{BrNO}_{4}$ calc. 441.0576, found 441.0582.

2-(6-(Diethylamino)benzofuran-2-yl)-6-((dodecyl(methyl)amino)methyl)-3-hydroxy-4H-chromen-4-one (3). 6-(Bromomethyl)-2-(6(diethylamino)benzofuran-2-yl)-3-hydroxy-4H-chromen-4-one (2) (1 eq., $150 \mathrm{mg}$ ) was dissolved in THF $(10 \mathrm{~mL})$ and then $N$-methyldodecylamine ( 2.5 eq., $210 \mu \mathrm{L}$ ) was added upon stirring. After $2 \mathrm{~h}$ of stirring, the mixture was analysed by TLC, showing full conversion. The crude product was then dried under vacuum and purified by column chromatography with $\mathrm{CH}_{2} \mathrm{Cl}_{2} / \mathrm{MeOH}$ (95/5) has eluent. Brown orange oil, yield 25\%. ${ }^{1} \mathrm{H}$ NMR (400 MHz, chloroform- $d$ ) $\delta$ $8.03(\mathrm{~d}, J=2.0 \mathrm{~Hz}, 1 \mathrm{H}), 7.67(\mathrm{dd}, J=8.4,2.0 \mathrm{~Hz}, 1 \mathrm{H}), 7.55(\mathrm{t}, J=4.4$ $\mathrm{Hz}, 2 \mathrm{H}), 7.40$ (d, $J=8.7 \mathrm{~Hz}, 1 \mathrm{H}), 6.79(\mathrm{~s}, 1 \mathrm{H}), 6.68$ (dd, $J=8.7,2.2$ $\mathrm{Hz}, 1 \mathrm{H}), 3.51$ (s, 2H), 3.38 (q, $J=7.0 \mathrm{~Hz}, 5 \mathrm{H}), 2.32(\mathrm{t}, J=8.0 \mathrm{~Hz}, 2 \mathrm{H})$, 2.13 (s, 3H), 1.45 (p, $J=7.7,6.9 \mathrm{~Hz}, 2 \mathrm{H}), 1.17$ (q, $J=6.7 \mathrm{~Hz}, 34 \mathrm{H})$, 0.84-0.73 (m, 6H). HR-LC-MS: $(\mathrm{m} / \mathrm{z}) \mathrm{C}_{35} \mathrm{H}_{48} \mathrm{~N}_{2} \mathrm{O}_{4}$ calc. 560.3614, found 560.3632 .

3-(((2-(6-(Diethylamino)benzofuran-2-yl)-3-hydroxy-4-oxo4H-chromen-6-yl)methyl)(dodecyl)-(methyl)ammonio)propane1-sulfonate (4). 2-(6-(Diethylamino)benzofuran-2-yl)-6-((dodecyl(methyl)amino)methyl)-3-hydroxy-4H-chromen-4-one (3) (1 eq., $50 \mathrm{mg}$ ) was dissolved in $\mathrm{CH}_{3} \mathrm{CN}(5 \mathrm{~mL})$ and then 1,3-propanesultone ( 3 eq., $23 \mu \mathrm{L}$ ) was added. The mixture was heated to reflux for $24 \mathrm{~h}$. The solvent was then removed under vacuum and the crude product was solved in $\mathrm{CH}_{2} \mathrm{Cl}_{2}$ and washed with a brine solution 3 times. It was used without further purification directly into the next step. Dark orange oil, yield 33\%.

3-((2-(6-(Diethylamino)benzofuran-2-yl)-3-methoxy-4-oxo4H-chromen-6-yl)methyl)(dodecyl)-(methyl)ammonio)propane1-sulfonate (FC12SM). 3-((2-(6-(Diethylamino)benzofuran-2-yl)3-hydroxy-4-oxo-4H-chromen-6-yl)methyl)(dodecyl)(methyl)ammonio)propane-1-sulfonate (4) (1 eq.; $15 \mathrm{mg}$ ) was firstly dissolved into $\mathrm{MeOH}(5 \mathrm{~mL})$, then $\mathrm{K}_{2} \mathrm{CO}_{3}$ (4 eq., $12 \mathrm{mg}$ ) and $\mathrm{CH}_{3} \mathrm{I}$ (10 eq., $31.92 \mathrm{mg}$ ) were added to the mixture. The reaction was stirred overnight at RT. After one night, 5 eq. of $\mathrm{K}_{2} \mathrm{CO}_{3}(15$ $\mathrm{mg}$ ) and a large excess of $\mathrm{CH}_{3} \mathrm{I}(1.14 \mathrm{~g})$ were added to the mixture. After a few hours, solvent was removed under vacuum and the crude product was purified by preparative TLC using $\mathrm{CH}_{2} \mathrm{Cl}_{2} / \mathrm{MeOH}(8 / 2)$ as eluent. Yellow orange powder, yield $85 \%$. ${ }^{1} \mathrm{H}$ NMR (400 MHz, methanol- $\left.d_{4}\right) \delta 8.26(\mathrm{~d}, J=2.1 \mathrm{~Hz}, 1 \mathrm{H}), 7.86$ (dd, $J=8.6,2.2 \mathrm{~Hz}, 1 \mathrm{H}), 7.74$ (d, $J=8.7 \mathrm{~Hz}, 1 \mathrm{H}), 7.65$ (s, 1H), $7.44(\mathrm{~d}, J=8.6 \mathrm{~Hz}, 1 \mathrm{H}), 6.76(\mathrm{~d}, J=9.5 \mathrm{~Hz}, 2 \mathrm{H}), 4.61(\mathrm{~s}, 2 \mathrm{H}), 3.94$ (s, 3H), 3.47-3.37 (m, 8H), $2.95(\mathrm{~s}, 3 \mathrm{H}), 2.81(\mathrm{t}, J=6.7 \mathrm{~Hz}, 2 \mathrm{H})$, 1.46-1.37 (m, 2H), 1.34-1.11 (m, 20H), 0.87-0.76 (m, 9H). HRLC-MS: $\left(\mathrm{M}+\mathrm{H}^{+}\right) \mathrm{C}_{39} \mathrm{H}_{56} \mathrm{~N}_{2} \mathrm{O}_{7} \mathrm{~S}$ calc. 696.3808, found 696.3793. Extinction coefficient in ethanol is $30000 \pm 3000 \mathrm{M}^{-1} \mathrm{~cm}^{-1}$ at $457 \mathrm{~nm}$.

3-(((2-(4-(Diethylamino)phenyl)-3-methoxy-4-oxo-4H-chromen6-yl)methyl)(dodecyl)(methyl)-ammonio)propane-1-sulfonate (F2N12SM). F2N12S (1 eq., $15 \mathrm{mg}$ ) was first dissolved into $\mathrm{MeOH}\left(5 \mathrm{~mL}\right.$ ), and then $\mathrm{K}_{2} \mathrm{CO}_{3}$ (2 eq., $10 \mathrm{mg}$ ) and $\mathrm{CH}_{3} \mathrm{I}$ (10 eq., $15 \mu \mathrm{L}$ ) were added to the mixture. The reaction was stirred for two days at RT. The solvent was then removed under vacuum and the crude product was purified by preparative TLC using $\mathrm{CH}_{2} \mathrm{Cl}_{2} / \mathrm{MeOH}(9 / 1)$ as eluent. Yellow orange powder, yield $80 \%$. 
${ }^{1} \mathrm{H}$ NMR (400 MHz, chloroform- $d$ ) $\delta 8.16(\mathrm{~d}, J=2.1 \mathrm{~Hz}, 1 \mathrm{H}), 8.02$ $(\mathrm{dd}, J=8.7,2.2 \mathrm{~Hz}, 1 \mathrm{H}), 7.96(\mathrm{~d}, J=8.9 \mathrm{~Hz}, 2 \mathrm{H}), 7.50(\mathrm{~d}, J=8.5$ $\mathrm{Hz}, 1 \mathrm{H}), 6.64$ (d, $J=9.1 \mathrm{~Hz}, 2 \mathrm{H}), 4.85$ (d, $J=13.1 \mathrm{~Hz}, 1 \mathrm{H}), 4.71$ $(\mathrm{d}, J=13.1 \mathrm{~Hz}, 1 \mathrm{H}), 3.83-3.71(\mathrm{~m}, 5 \mathrm{H}), 3.37$ (q, $J=7.1 \mathrm{~Hz}, 4 \mathrm{H})$, 3.10-2.93 (m, 6H), 2.58-2.28 (m, 5H), $1.84(\mathrm{~s}, 1 \mathrm{H}), 1.71(\mathrm{~s}, 1 \mathrm{H})$, 1.30-1.07 (m, 24H), $0.78(\mathrm{t}, J=6.8 \mathrm{~Hz}, 3 \mathrm{H})$. HR-LC-MS: $\left(\mathrm{M}+\mathrm{H}^{+}\right)$ $\mathrm{C}_{37} \mathrm{H}_{56} \mathrm{~N}_{2} \mathrm{O}_{6} \mathrm{~S}$ calc. 656.3859 , found 656.3556. Extinction coefficient in ethanol is $29000 \pm 3000 \mathrm{M}^{-1} \mathrm{~cm}^{-1}$ at $412 \mathrm{~nm}$.

\subsection{Lipid vesicles}

Dioleoylphosphatidylcholine (DOPC) and cholesterol were purchased from Sigma-Aldrich. Bovine brain sphingomyelin (SM) was from Avanti Polar Lipids (Alabaster, AL). Large unilamellar vesicles (LUVs) were obtained by the extrusion method as previously described..$^{32}$ Briefly, a suspension of multilamellar vesicles, prepared from the hydrated film of lipids, was extruded with the Lipex Biomembranes extruder (Vancouver, Canada). The size of the filters was first $0.2 \mu \mathrm{m}$ (7 passages) and thereafter $0.1 \mu \mathrm{m}$ (10 passages). This generates monodisperse LUVs with a mean diameter of $0.11 \mu \mathrm{m}$ as measured with a Malvern Zetamaster 300 (Malvern, U.K.). LUVs were labelled by adding aliquots (generally $2 \mu \mathrm{L}$ ) of probe stock solutions in dimethyl sulfoxide to $1 \mathrm{~mL}$ solutions of vesicles. Since the probe binding kinetics is very rapid, the fluorescence experiments were performed a few minutes after addition of the aliquot. $20 \mathrm{mM}$ phosphate buffer, $\mathrm{pH}$ 7.4, was used in these experiments. Concentrations of the probes and lipids were generally 0.4 and $200 \mu \mathrm{M}$, respectively, unless indicated.

\subsection{Cell lines, culture conditions, and treatment}

HeLa cells (ATCC) were cultured in Dulbecco's modified Eagle medium (D-MEM, Low glucose, +GlutaMAX, Gibco-Invitrogen) supplemented with $10 \%$ (v/v) fetal bovine serum (FBS, Lonza), and $1 \%$ antibiotic solution (penicillin-streptomycin, GibcoInvitrogen) in a humidified incubator with $5 \% \mathrm{CO}_{2}$ atmosphere at $37{ }^{\circ} \mathrm{C}$. Cells cultures passages were realized every $2-3$ days.

In fluorescence spectroscopy experiments, HeLa cells were detached by trypsinization. DMEM medium was first removed from the culture dish, and cells were washed two times with DPBS. Trypsin $1 \times$ (LONZA) solution in DPBS was added to the cells and the cells were incubated at $37{ }^{\circ} \mathrm{C}$ for $4 \mathrm{~min}$. The solution of trypsinized cells was then diluted by DPBS, transferred to Falcon tubes and centrifuged for $5 \mathrm{~min}$. The washing procedure was repeated one more time with HBSS solution. To stain the cell suspension with the probes, an appropriate aliquot of their stock solution in DMSO was added to $0.5 \mathrm{~mL}$ of HBSS buffer, and after vortexing, the solution was immediately added to $0.5 \mathrm{~mL}$ of the cell suspension to obtain a final probe concentration of $40 \mathrm{nM}(<0.25 \%$ DMSO $)$ and a cell concentration of $5 \times 10^{5}$ to $10^{6}$ cells per $\mathrm{mL}$. It should be noted that only freshly prepared solutions of the probes in HBSS should be used ( $<1 \mathrm{~min}$ ) for cell staining, because of the slow aggregation of the probe in water. Before measurements, the cell suspension with the probe was incubated for $7 \mathrm{~min}$ at RT in the dark.
For microscopy studies with the probes, attached HeLa cells were washed two times by gentle rinsing with HBSS. Then, a freshly prepared solution of F2N12S, F2N12SM or FC12SM in Opti-MEM (or HBSS) was added to the cells to a final probe concentration of $50 \mathrm{nM}(<0.25 \%$ DMSO volume $)$ and incubated for $7 \mathrm{~min}$ in the dark at RT. The obtained samples were imaged directly without washing.

For tri-colour fluorescence imaging, HeLa cells were transfected by a plasmid coding mCherry. $3 \times 10^{5}$ HeLa cells were seeded in $35 \mathrm{~mm}$ glass coverslips ( $\mu$-Dish IBIDI, Germany) in DMEM supplemented with 10\% FBS and antibiotics (penicillin $100 \mathrm{UI} \mathrm{mL}{ }^{-1}$, streptomycin $100 \mathrm{UI} \mathrm{mL}^{-1}$ ) and kept at $37^{\circ} \mathrm{C}$ in a $5 \% \mathrm{CO}_{2}$ atmosphere. Transfection was performed at 24 hours post-seeding with $1 \mu \mathrm{g}$ of pcDNA3.1 mCherry plasmid using jetPEI $^{\text {тм }}$ (PolyPlus transfection, France) according to supplier's recommendations. All observations were done between 16-24 hours post DNA transfection. To stain lysosomes in green, LysoTracker® Green DND-26 (Life technologies) was added to the cells at $50 \mathrm{nM}$ final concentration and incubated for $30 \mathrm{~min}$ at $37^{\circ} \mathrm{C}$. Then F2N12SM was added as described above.

\subsection{Fluorescence spectroscopy and microscopy}

Absorption spectra were recorded on a Cary 4 spectrophotometer (Varian) and fluorescence spectra on a Fluorolog (Jobin Yvon, Horiba) spectrofluorometer. Fluorescence emission spectra were systematically recorded at $410 \mathrm{~nm}$ excitation wavelength at room temperature, unless indicated. All spectra were corrected for the fluorescence of the corresponding blank (suspension of cells or lipid vesicles without the probe) and wavelength-dependent sensitivity of the detector. Fluorescence quantum yield were measured using $4^{\prime}$-(dimethylamino)-3hydroxyflavone in methanol as a reference $(27 \%) .{ }^{33}$

Confocal microscopy experiments were performed by using a Leica TCS SPE-II microscope with HXC PL APO $63 \times / 1.40$ OIL CS objective. The excitation was provided by 405 and $488 \mathrm{~nm}$ laser and the images were processed with the Image $\mathrm{J}$ software.

\section{Results and discussion}

\subsection{Design and synthesis}

F2N12SM is an analogue of F2N12S, where the 3-hydroxy group is methylated (Fig. 1). It was prepared by direct methylation of F2N12S with methyl iodide in acetonitrile (Fig. S1 in ESI $\dagger$ ). To prepare FC12SM (Fig. 1), 6-(diethylamino)benzofuran-2-carbaldehyde $^{30}$ was condensed with 5-chloromethyl-2-hydroxyacetophenone $^{31}$ in basic conditions and then oxidized in the presence of hydrogen peroxide into the corresponding 3hydroxychromone derivative (Fig. S2 in ESI†). It was then reacted with $N$-methyl-dodecylamine and the obtained tertiary amine was quaternized with 1,3-propanesultone. The 3-hydroxy group of the chromone was then methylated to obtain the FC12SM probe. The final probes were purified by thin layer chromatography and their structure was confirmed by NMR and mass spectrometry. 


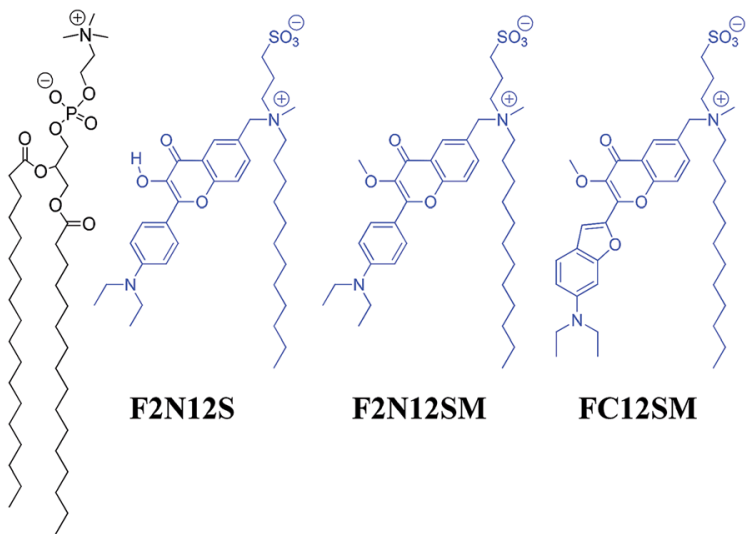

Fig. 1 Chemical structures of F2N12S and the new membrane probes, F2N12SM and FC12SM, and their hypothetic location with respect to a lipid (black) of the membrane bilayer.

\subsection{Fluorescence spectroscopy in model membranes}

F2N12SM and FC12SM showed very poor fluorescence intensity in aqueous media ( $\mathrm{QY}<0.5 \%$ for both probes), but they were highly emissive in organic solvents (Table 1). On addition of large unilamellar vesicles (LUVs), the fluorescence intensity of both probes grew rapidly with lipid concentration and reached stable values at lipid/probe ratios $\geq 125$ (Fig. 2), indicating that above this probe/lipid ratio nearly all dye molecules were bound to lipids. These data indicate an efficient binding of the probes to lipid membranes. Remarkably, the fluorescence intensity increased $>200$-fold and the emission band shifted by 30 and 65 $\mathrm{nm}$ to the blue for F2N12SM and FC12SM, respectively (Fig. 2). The position of the emission band also stabilized at lipid/probe ratios $\geq 125$, confirming that optimal binding was achieved in these conditions. The obtained quantum yields in DOPC vesicles were 33 and 37\%, for F2N12SM and FC12SM, respectively, which confirmed their efficient binding to the lipid vesicles. The fluorogenic response of F2N12SM and FC12SM to membrane binding can have two mechanisms. On one hand, their 3methoxychromone moieties, owing to the charge transfer character, exhibit efficient quenching in polar media, particularly in water. ${ }^{29}$ Therefore, the transfer of the probes from polar

Table 1 Spectroscopic properties of F2N12SM and FC12SM in different media $^{a}$

\begin{tabular}{lllll}
\hline Probe & Medium & $\lambda_{\text {abs }}, \mathrm{nm}$ & $\lambda_{\text {fluo }}, \mathrm{nm}$ & QY, \% \\
\hline \multirow{2}{*}{ F2N12SM } & Water & 412 & 537 & $<0.5$ \\
& Acetone & 398 & 501 & 61 \\
& Dioxane & 400 & 471 & 56 \\
& DOPC LUVs & 402 & 480 & 33 \\
FC12SM & Water & 445 & 621 & $<0.5$ \\
& Acetone & 445 & 578 & 69 \\
& Dioxane & 449 & 536 & 51 \\
& DOPC LUVs & 450 & 544 & 37
\end{tabular}

${ }^{a} \lambda_{\text {abs }}$ and $\lambda_{\text {fluo }}$ are positions of the absorption and fluorescence maxima, respectively (nm); QY is the fluorescence quantum yield (\%).

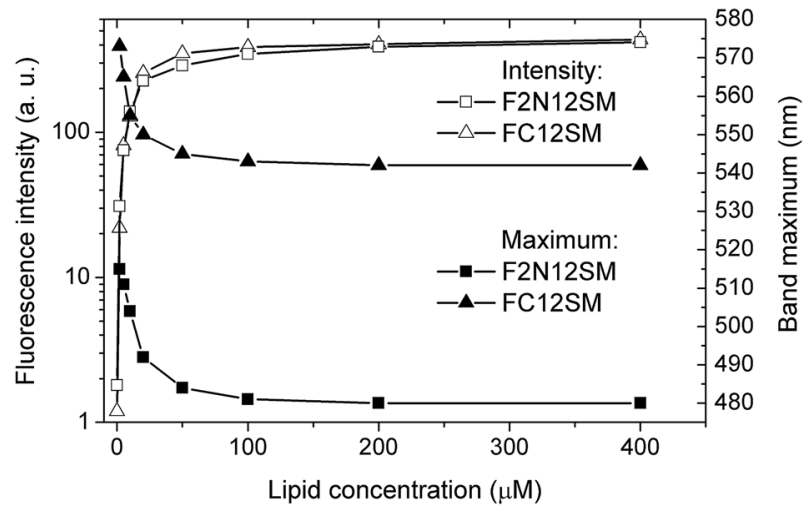

Fig. 2 Fluorescence intensity (open symbols) and emission maximum (filled symbols) of F2N12SM (squares) and FC12SM (triangles) in lipid vesicles (composed of DOPC) at different concentrations of lipids. Probe concentration was $0.4 \mu \mathrm{M}$.

aqueous medium to apolar lipid membrane should drastically increase the fluorescence efficiency of the probes. On the other hand, our works on Nile Red-based probe $\mathrm{NR}_{12} \mathrm{~S}^{\mathbf{1 3}}$ and its analogue, ${ }^{34}$ presenting similar structure, as well as other recent reports $^{35,36}$ suggest that membrane probes can be self-quenched due to aggregation in water and then disaggregate after binding to lipid membrane. We expect that both environment-sensitivity and disaggregation of F2N12SM and FC12SM contribute to their remarkable fluorogenic character.

In lipid vesicles composed of dioleoylphosphatidylcholine (DOPC), F2N12SM and FC12SM showed an absorption maximum around 400 and $450 \mathrm{~nm}$, respectively (Fig. 3). Thus, both probes were compatible with the $405 \mathrm{~nm}$ laser source, commonly used in fluorescence microscopy. Moreover, they exhibited a single emission band, centred at 480 and $544 \mathrm{~nm}$ (Fig. 3), confirming that methylation of the 3-hydroxy group prevented the formation of the tautomer form observed for F2N12S. ${ }^{25}$ According to our earlier studies of the corresponding 3-methoxychromones in organic solvents, ${ }^{29}$ these emission maxima indicate a relatively apolar environment similar to the one of ethyl acetate-dichloromethane (dielectric constant $\varepsilon=6$ 9), suggesting the insertion of the fluorophores of both probes into apolar ester region of the lipid bilayer. In comparison with

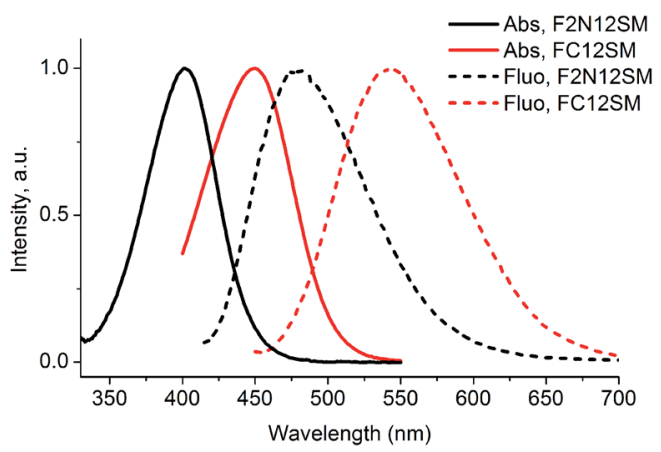

Fig. 3 Normalized absorption and fluorescence spectra of F2N12SM and FC12SM in lipid vesicles composed of DOPC. Probe and lipid concentrations were 0.4 and $200 \mu \mathrm{M}$, respectively. 
the commercially available blue dyes of the coumarin (aminomethylcoumarin acetate, AMCA) or pyrene (Cascade Blue) families, our probes exhibit significantly larger Stokes shifts, which are of key importance for minimizing contribution of the auto-fluorescence in microscopy applications. These large Stokes shifts originate from the dipolar nature of these chromone derivatives, which ensures significant solvent relaxation of the fluorophores. ${ }^{37}$ As these dyes are solvatochromic, we checked their sensitivity to changes in the lipid composition. Surprisingly, the new dyes showed relatively small variation of their emission maximum for different lipid compositions corresponding to liquid crystalline (DOPC), liquid disordered (DOPC/cholesterol) and liquid ordered (sphingomyelin/ cholesterol) phases (Fig. 4). This poor sensitivity to lipid composition is in clear contrast with F2N12S or other solvatochromic membrane probes based on Nile Red ${ }^{\mathbf{1 3}}$ and Laurdan. ${ }^{23,38}$ Nevertheless, this property is of interest for standard imaging and FRET applications, which require stable position of the emission maximum.

Then, we evaluated the photostability of the new probes bound to lipid membranes in comparison to their parent analogue F2N12S. After $1 \mathrm{~h}$ of illumination (light flux of $\sim 1 \mathrm{~mW}$ $\mathrm{cm}^{-2}$ ), the fluorescence decreased only by $16 \%$ and $14 \%$ for F2N12SM and FC12SM, respectively, whereas for F2N12S the corresponding fluorescence loss was as high as 88\% (Fig. 5). This strongly improved photostability is in agreement with our previous report on 3-methoxychromones in organic solvents ${ }^{29}$ and is explained by the absence in these dyes of the excited state intramolecular proton transfer generating the less photostable tautomeric form.

\subsection{Application for cellular imaging}

After addition to suspensions of HeLa cells, the new probes exhibited a single emission band similar to that observed in model membranes composed of DOPC/cholesterol mixture

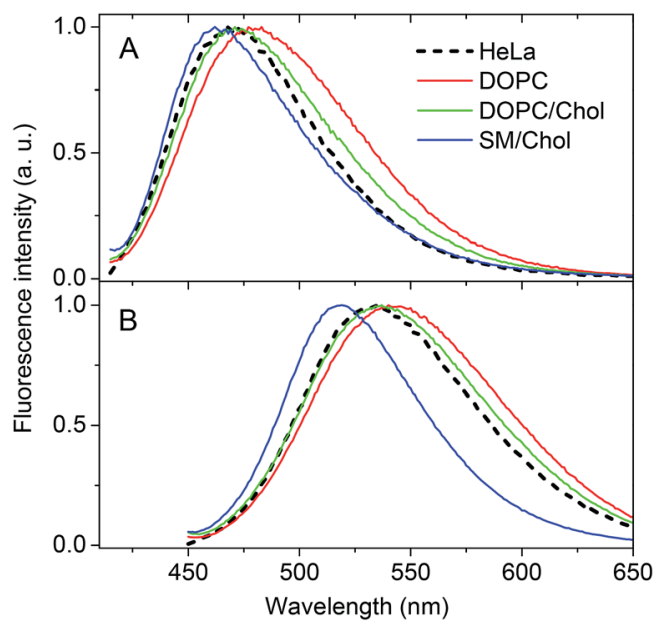

Fig. 4 Normalized fluorescence spectra of probe F2N12SM (A) and FC12SM (B) in vesicles of different lipid compositions and in HeLa cells. Probe concentrations were $0.4 \mu \mathrm{M}$ and $20 \mathrm{nM}$ in lipid vesicles and HeLa cells, respectively.

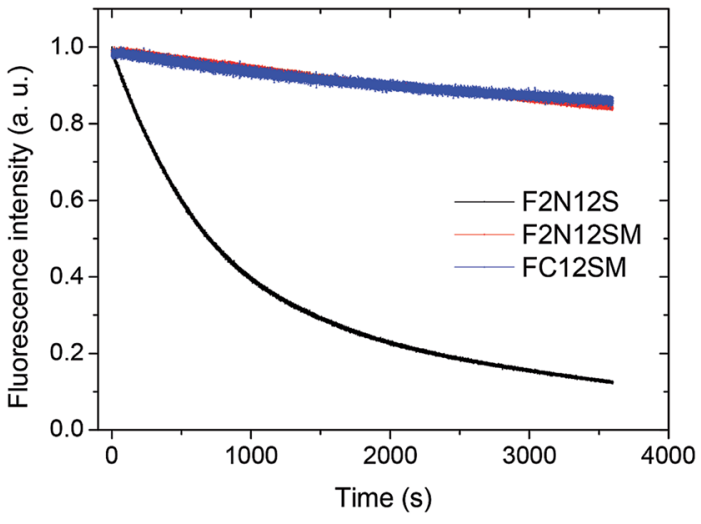

Fig. 5 Photostability of the new probes in DOPC vesicles compared to the parent F2N12S probe. Fluorescence emission at the corresponding emission maximum was recorded as a function of the illumination time. Excitation wavelength was $410 \mathrm{~nm}$, where the extinction coefficient for both probes is close and the excitation light intensity was $\sim 1$ $\mathrm{mW} \mathrm{cm}^{-2}$. Probe and lipid concentrations were 0.4 and $200 \mu \mathrm{M}$, respectively.

(Fig. 4). The fluorescence intensity and the band shape stabilized within $<5 \mathrm{~min}$. The new probes were then added to adherent HeLa cells and studied by confocal fluorescence microscopy. A clear membrane staining was observed for both new probes. They exhibited excellent fluorescence contrast even at low probe concentrations $(50 \mathrm{nM})$, with a signal-tobackground ratio of 15-20, while for our reference membrane probe F2N12S it was only 3-4 (Fig. 6B-D). Fluorescence imaging at different concentrations of probes revealed that already at 20 nM of F2N12SM we obtained high-quality images, in contrast to F2N12S that needed concentrations $>100 \mathrm{nM}$ (Fig. S4 $\dagger$ ), in line with our earlier studies of F2N12S. ${ }^{25}$ To the best of our knowledge, these are the first blue dyes that can be used at such low concentrations for cell membrane staining. Despite these low concentrations, the cell auto-fluorescence remained negligible, which is due to the efficient binding of the probes to cell plasma membranes as well as their high brightness (extinction coefficient $\times$ quantum yield $\sim 30000 \times 0.4$ ) and large Stokes shift allowing detection far from the excitation wavelength. Importantly, the blue emission region is very convenient, as biologists use extensively green and red emission channels with fluorescent proteins and organic dyes. Particularly interesting in this respect is F2N12SM, because its absorption maximum matches perfectly with the $405 \mathrm{~nm}$ laser excitation, while its emission does not overlap with the green channel. We evaluated the compatibility of this probe with markers representative of the most commonly used colours. The first one is LysoTracker ${ }^{\circledR}$ Green DND-26, which labels lysosomes and uses the same instrumental settings as fluorescein, AlexaFluor 488, and eGFP. The second one is mCherry, which stains the cytoplasm and corresponds spectrally to common Rhodamine and Cyanine 3 dyes. From the obtained multi-colour images (Fig. 6E-H), it can be seen that F2N12SM clearly stains the plasma membranes in the presence of the other markers (Fig. 6E). Moreover, its fluorescence is not detectable in the green (Fig. 6F) and red (Fig. 6G) 

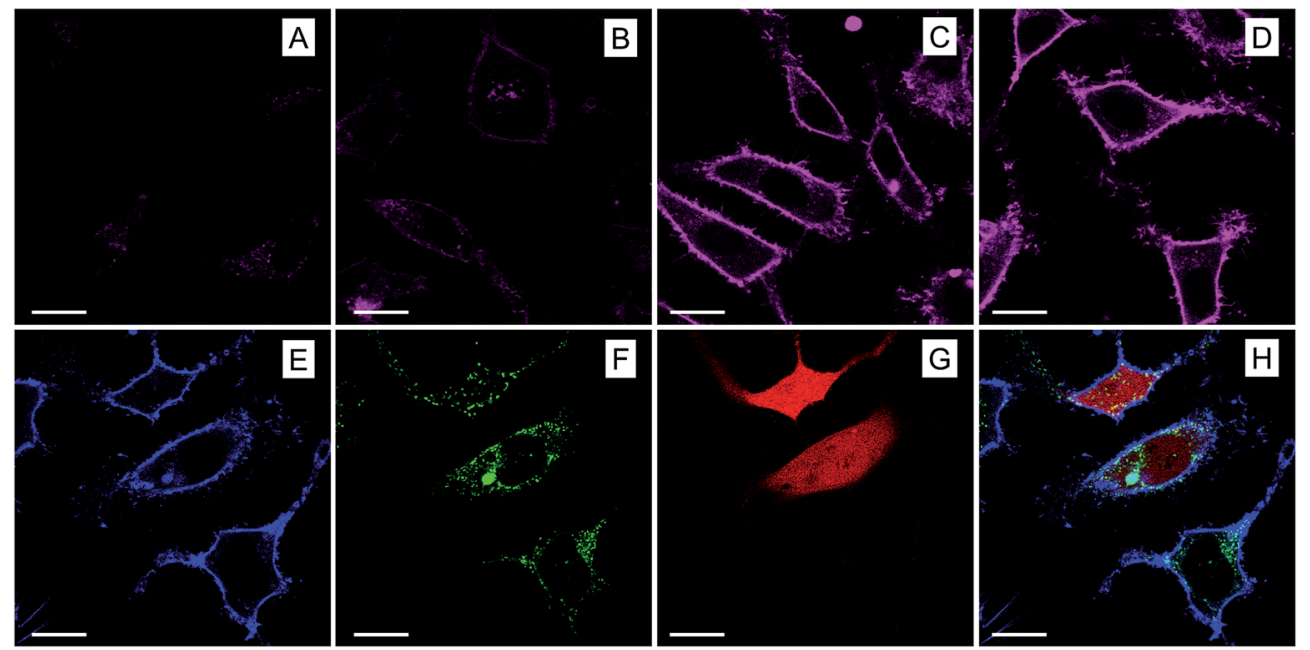

Fig. 6 Fluorescence confocal images of HeLa cells without probes (A) and stained with F2N12S (B), F2N12SM (C) or FC12SM (D) at 50 nM concentrations. Excitation wavelength was $405 \mathrm{~nm}$; emission was detected between 450 and $550 \mathrm{~nm}$ (A-C) or between $460-610 \mathrm{~nm}$ (D). (E-H) Multicolour confocal imaging using F2N12SM (blue, E), LysoTracker® Green DND-26 (green, F) and mCherry (red, G) and merge of the three images $(H)$. Excitation/emission wavelengths were: 405/450-500 nm (E); 488/505-550 nm (F) and 561/580-670 nm (G). HeLa cells were transfected with the mCherry plasmid, so that only some fraction of the cells expressed this protein. Opti-MEM buffer was used. Scale bar is $20 \mu \mathrm{m}$.

channels, indicating the absence of cross-talk between the channels. Thus, F2N12SM is perfectly compatible with both LysoTracker® Green DND-26 and mCherry, allowing RGB imaging. Therefore, this new probe could be used to stain the cellular contour with a complementary blue colour, similarly to Hoechst or DAPI used for staining nucleus.

In conclusion, we describe fluorescent membrane probes with convenient absorption in a blue region allowing their combination with common green and red cellular markers for multicolor imaging. To overcome the problem of autofluorescence common for blue dyes, our probes were developed with several key features. Firstly, these probes are fluorogenic, so that they turn-on their fluorescence $>100$-fold after nearly quantitative binding to the lipid membranes. Secondly, they exhibit high brightness and large Stokes shift, which enable their use at low concentrations (20 nM), applying a simple staining protocol. We expect that these new probes may become as common for multicolour cellular staining as blue nucleus staining dye Hoechst or DAPI.

\section{Acknowledgements}

This work was supported by ANR JCJC (ANR-11-JS07-014-01), CNRS, and the University of Strasbourg. We warmly thank Pascale Buisine, Dr Justine Viéville and Patrick Wehrung from the Service de Chimie Analytique (SCA) for LC-MS and RMN analyses.

\section{References}

1 L. D. Lavis and R. T. Raines, ACS Chem. Biol., 2008, 3, 142155.
2 B. N. G. Giepmans, S. R. Adams, M. H. Ellisman and R. Y. Tsien, Science, 2006, 312, 217-224.

3 M. Fernández-Suárez and A. Y. Ting, Nat. Rev. Mol. Cell Biol., 2008, 9, 929-943.

4 H. Kobayashi, M. Ogawa, R. Alford, P. L. Choyke and Y. Urano, Chem. Rev., 2010, 110, 2620-2640.

5 A. P. Demchenko, Y. Mély, G. Duportail and A. S. Klymchenko, Biophys. J., 2009, 96, 3461-3470.

6 A. S. Klymchenko and R. Kreder, Chem. Biol., 2014, 21, 97113.

7 C. W. Cairo, J. A. Key and C. M. Sadek, Curr. Opin. Chem. Biol., 2010, 14, 57-63.

8 L. M. S. Loura and J. P. P. Ramalho, Molecules, 2011, 16, 5437-5452.

9 Z. Darwich, A. S. Klymchenko, D. Dujardin and Y. Mély, RSC Adv., 2014, 4, 8481-8488.

10 D. A. Doval, A. Fin, M. Takahashi-Umebayashi, H. Riezman, A. Roux, N. Sakai and S. Matile, Org. Biomol. Chem., 2012, 10, 6087-6093.

11 A. Fin, A. Vargas Jentzsch, N. Sakai and S. Matile, Angew. Chem., Int. Ed., 2012, 51, 12736-12739.

12 S. Redon, J. Massin, S. Pouvreau, E. De Meulenaere, K. Clays, Y. Queneau, C. Andraud, A. Girard-Egrot, Y. Bretonniére and S. Chambert, Bioconjugate Chem., 2014, 25, 773-787.

13 O. A. Kucherak, S. Oncul, Z. Darwich, D. A. Yushchenko, Y. Arntz, P. Didier, Y. Mély and A. S. Klymchenko, J. Am. Chem. Soc., 2010, 132, 4907-4916.

14 D. Lingwood and K. Simons, Science, 2010, 327, 46-50.

15 H. Mizuno, M. Abe, P. Dedecker, A. Makino, S. Rocha, Y. Ohno-Iwashita, J. Hofkens, T. Kobayashi and A. Miyawaki, Chem. Sci., 2011, 2, 1548-1553.

16 E. Sezgin, I. Levental, M. Grzybek, G. Schwarzmann, V. Mueller, A. Honigmann, V. N. Belov, C. Eggeling, 
Ü. Coskun, K. Simons and P. Schwille, Biochim. Biophys. Acta, 2012, 1818, 1777-1784.

17 L. A. Bagatolli, Biochim. Biophys. Acta, 2006, 1758, 1541-1556. 18 M. A. Model, J. L. Reese and G. C. Fraizer, Cytometry, Part A, 2009, 75, 874-881.

19 J. E. González and R. Y. Tsien, Chem. Biol., 1997, 4, 269-277.

20 S. Bolte, C. Talbot, Y. Boutte, O. Catrice, N. D. Read and B. Satiat-Jeunemaitre, J. Microsc., 2004, 214, 159-173.

21 J. G. Kuhry, P. Fonteneau, G. Duportail, C. Maechling and G. Laustriat, Cell Biophys., 1983, 5, 129-140.

22 L. Jin, A. C. Millard, J. P. Wuskell, X. Dong, D. Wu, H. A. Clark and L. M. Loew, Biophys. J., 2006, 90, 2563-2575.

23 H. M. Kim, H. J. Choo, S. Y. Jung, Y. G. Ko, W. H. Park, S. J. Jeon, C. H. Kim, T. Joo and B. R. Cho, ChemBioChem, 2007, 8, 553-559.

24 X. Zhang, C. Wang, L. Jin, Z. Han and Y. Xiao, ACS Appl. Mater. Interfaces, 2014, 6, 12372-12379.

25 V. V. Shynkar, A. S. Klymchenko, C. Kunzelmann, G. Duportail, C. D. Muller, A. P. Demchenko, J. M. Freyssinet and Y. Mely, J. Am. Chem. Soc., 2007, 129, 2187-2193.

26 N. C. Shaner, R. E. Campbell, P. A. Steinbach, B. N. G. Giepmans, A. E. Palmer and R. Y. Tsien, Nat. Biotechnol., 2004, 22, 1567-1572.
27 X. Li, X. Gao, W. Shi and H. Ma, Chem. Rev., 2014, 114, 590659.

28 A. Nadler and C. Schultz, Angew. Chem., Int. Ed., 2013, 52, 2408-2410.

29 O. A. Kucherak, L. Richert, Y. Mély and A. S. Klymchenko, Phys. Chem. Chem. Phys., 2012, 14, 2292-2300.

30 A. S. Klymchenko, T. Ozturk, V. G. Pivovarenko and A. P. Demchenko, Tetrahedron Lett., 2001, 42, 7967-7970.

31 A. S. Klymchenko, G. Duportail, T. Ozturk, V. G. Pivovarenko, Y. Mély and A. P. Demchenko, Chem. Biol., 2002, 9, 11991208.

32 M. J. Hope, M. B. Bally, G. Webb and P. R. Cullis, Biochim. Biophys. Acta, 1985, 812, 55-65.

33 S. M. Ormson, R. G. Brown, F. Vollmer and W. Rettig, J. Photochem. Photobiol., A, 1994, 81, 65.

34 Y. Niko, Y. Arntz, Y. Mely, G. Konishi and A. S. Klymchenko, Chem.-Eur. J., 2014, 20, 16473-16477.

35 M. Montalti, G. Battistelli, A. Cantelli and D. Genovese, Chem. Commun., 2014, 50, 5326-5329.

36 D. Zhai, W. Xu, L. Zhang and Y. T. Chang, Chem. Soc. Rev., 2014, 43, 2402-2411.

37 P. Jurkiewicz, J. Sýkora, A. Olzyńska, J. Humpolíčková and M. Hof, J. Fluoresc., 2005, 15, 883-894.

38 T. Parasassi, E. K. Krasnowska, L. Bagatolli and E. Gratton, J. Fluoresc., 1998, 8, 365-373. 